Schöttle, A., Christensen, R., \& Arroyo, P. (2019). "Does Choosing by Advantages Promote Inclusiveness in Group Decision-Making?" In: Proc. 27th Annual Conference of the International. Group for Lean Construction (IGLC), Pasquire C. and Hamzeh F.R. (ed.), Dublin, Ireland, pp. 797-808. DOI: https://doi.org/10.24928/2019/0209. Available at: 〈www.iglc.net>.

\title{
DOES CHOOSING BY ADVANTAGES PROMOTE INCLUSIVENESS IN GROUP DECISION-MAKING?
}

\author{
Annett Schöttle ${ }^{1}$, Randi Christensen ${ }^{2}$, and Paz Arroyo ${ }^{3}$
}

\begin{abstract}
In a construction project, decisions should be made by the team member or group which is best prepared to handle the decision. Often this is not the case due to hierarchical structures, time pressure and a lack of trust. Previous work showed that a significant number of female Lean practitioners found their ideas and input were not taken seriously. Empowering people in an organization and in the field means to include them in the decision-making process. Choosing by Advantages (CBA) is a structured multi-criteria decision-making method that bases decisions on the importance of advantages among different alternatives. In CBA advantages are anchored to relevant facts, so decision-makers can make a sound and inclusive decision. In previous work it was reported that CBA is transparent and traceable for people not involved in the decision-making process. In conclusion, the authors found evidence that CBA promotes inclusiveness to overcome groupthink and promotes psychological safety, but no direct evidence was found to overcome gender bias.
\end{abstract}

\section{KEYWORDS}

Choosing by advantages, collaboration, decision-making, inclusiveness, psychological safety.

\section{INTRODUCTION}

The construction industry is coming to rely more and more on integration between different parties - such as architects, owners, general contractors and subcontractors - so that they work as one team on a project (Matthews and Howell 2005). The integration of the different team members needs a high level of coordination and structure across the various processes such as decision-making. By reviewing several different studies, Collins and Guetzkow

1 Senior Consultant, Refine Projects AG, Schelmenwasenstraße 34, 70567 Stuttgart, Germany, +4915156561529 , annett.schoettle @ refineprojects.com and Founder and Co-Director, CollabDecisions, www.collabdecisions.com.

2 Lean Manager, Lower Thames Crossing, COWI, UK, RMCH@ cowi.com and Founder and Co-Director, CollabDecisions, www.collabdecisions.com.

3 DPR Quality Leader, San Francisco, CA, PazA@dpr.com, and Founder and Co-Director, CollabDecisions, www.collabdecisions.com. 
(1964) generalize that, in comparison to individual decision-making and synthesized ${ }^{4}$ group decision-making, interactive group decision-making results in higher quality decisions, because of higher resource availability, as more and better alternatives can be discovered. On the other hand, skilled individuals could get slowed down in a group, because they have to listen to less skilled group members. Furthermore, the more people are interactively involved in the decision-making, the more effort and time is necessary to decide (Collins and Guetzkow 1964). Another fact that should be considered is the relevance of social motives such as acceptance or relationships that impact the individual's behaviour when working in a group (Collins and Guetzkow 1964). Construction projects contain a series of team decisions, including strategic decisions, because they affect different parties. Although decision-making is key for project progress, group decisionmaking is not thoughtfully designed in projects (Schöttle et al. 2018). Often responsibility, structure, documentation, reporting and time track are not defined upfront, making it difficult for the team to decide and receive decisions on time. Schöttle et al. (2018) point out how a decision-making process should be designed by analyzing four projects, and recommend applying Choosing by Advantages (CBA) as the decision-making method in diverse groups. $\mathrm{CBA}$ is a multi-criteria decision-making method that bases decisions on the importance of advantages among different alternatives. In CBA, advantages are anchored to relevant facts, which are called attributes of the alternatives, so decisionmakers can make a sound decision (Suhr 1999). CBA presents several benefits in the literature, but how it affects inclusiveness for group decisions has not been studied.

This paper will analyse how to include the different team members when making group decisions by focusing on three issues: (1) avoiding groupthink, (2) promoting psychological safety, and (3) hearing ideas from gender-diverse groups. The research question is therefore: Does CBA promote inclusiveness to overcome group thinking, promote psychological safety, and avoid gender bias? In this paper, in order to answer the question, first the literature is analysed to understand the three issues. Second, a combination of case study and action research is used to collect data ex-post and ex-ante of the implementation of CBA. Third, the findings from action and case study research are jointly discussed based on the findings from the literature. Finally, we conclude in the last section by reflecting on the limitations of this study.

\section{LITERATURE REVIEW}

\section{INCLUSIVENESS IN DECISION-MAKING}

According to the Cambridge Dictionary, inclusiveness is "the quality of including many different types of people and treating them all fairly and equally". In group decisionmaking it is important to include the right team members in the group decision-making (Collins and Guetzkow 1964). Shore et al. (2011) define inclusion as "the degree to which an employee perceives that he or she is an esteemed member of the work group through experiencing treatment that satisfies his or her needs for belongingness and uniqueness"

4 This means that each group member first makes their own decision, and then these are discussed in the group and a final overall decision made. 
(p. 1265). The individual perception of inclusiveness depends on workplace climate, leadership and human resources practices (Shore et al. 2011; Randel et al. 2016). In terms of leadership, Nembhard and Edmondson (2006) define leader inclusiveness as "words and deeds by a leader [...] that indicate an invitation and appreciation for others' contributions" (p. 947). Leadership inclusiveness has a tremendous impact in creating an environment where the individuals of the decision-making group feel included. Shore et al. (2011) argue that groups which value and respect diversity (high belongingness) as well as appreciate diversity as a resource (high value in uniqueness) have a high degree of inclusion. In comparison, if belongingness and the value of uniqueness are low, exclusion results (Shore et al. 2011). According to Patrick and Kumar (2012), managing diversity successfully "can lead to more committed, better satisfied, better performing employees and potentially better financial performance for an organization" (p. 1). Given the context of construction projects around the world, with a high concentration of males in decision-making roles and hierarchical organizations, the authors decided to study inclusiveness focusing on three issues: (1) avoiding groupthink, (2) promoting psychological safety, and (3) hearing ideas from gender diverse groups. The following sections present a literature review on these issues.

\section{Groupthink}

There are many decision-making biases identified in the literature, such as status quo tendency, halo effect, anchoring, group thinking, sunk cost, confirmation bias, social bias, cognitive bias, gender bias and noise, leading to poor decisions. Groupthink is especially relevant to the topic of inclusiveness because it is caused by a lack of diverse thinking. Janis (1982) analyzed the group cohesiveness and the decision-making of a group and initiated the term groupthink as the "mode of thinking that people engage in when they are deeply involved in a cohesive in-group, when the members' striving for unanimity overwrite their motivation to realistically appraise alternatives courses for action" (p. 9). Ellis and Fisher (1994) describe groupthink similar to Janis (1982), as "the phenomenon that occurs when members of a highly cohesive group disregard [alternatives]" (p. 308) to maintain unanimity. It is the pressure to conform to norms of the in-group (Janis 1982; Ellis and Fisher 1994), a "collective pattern of defensive avoidance" (Janis and Mann 1979, p. 129). Thus, it is the tendency of concurrent seeking, the avoidance of disagreement and argumentation (Janis and Mann 1979, 1982; Johnson and Johnson 2009), it leads to illusion, and causes mistakes that easily could be avoided (Forsyth 1990). In consequence, defective decision-making results, because of mindless cohesion, pressuring nonconformists, a failing to reward critical thinking, a tendency for justification (Ellis and Fisher 1994), self-censorship of deviations, stereotyped views, protection from adverse information (Janis and Mann 1979) and so selective bias in using facts, incomplete check for alternatives and factors, no consultation of experts (Janis 1982), insufficient risk assessment, poor data collection and information processing, and the failure to participate (Johnson and Johnson 2009). According to Janis and Mann (1979), the root causes of the 
listed symptoms besides the previous named cohesiveness ${ }^{5}$, are insulation of the group ("insulated from criticism" (Forsyth 1990, p. 299)), directive leadership, decisional stress, and a lack of methodical procedures for assessment. If only one root cause exists in a group, the group is not adopting groupthink, but "if two or more of these factors are present [...] the likelihood of groupthink becomes much greater" (Forsyth 1990, p. 301). Thus, decisions are not analyzed critically (Putnam and Stohl 1996), because discussions regarding disagreement just disappear (Forsyth 1990), and contingency plans are not provided (Janis 1982). Avoiding group thinking is key for making good decisions in construction projects.

\section{Psychological Safety}

Lack of psychological safety occurs when project team members are unwilling to speak up freely, because of disapproval, negative consequences, or the concern that they will be seen as incompetent (Edmondson 1999; Nembhard and Edmondson 2006). The reactions they think they will receive are based on a lack of feeling respected and a lack of confidence (Edmondson 1999). This also impacts learning from failure and makes it obvious that psychological safety and learning from failure are strongly related to each other (Hirak 2012). Nembhard and Edmondson (2006) found out that leader inclusiveness can have a positive impact on psychological safety in teams. Hirak (2012) analyzed the correlation between leadership inclusiveness and psychology, gathering data via a survey in a large hospital, and confirmed that leaders with a high level of inclusiveness create a working environment with high psychology safety. The results were confirmed by Randel et al. (2016). Promoting psychological safety is key for decision-making in construction projects.

\section{Gender Diversity}

In the decision-making literature it is argued that, the more heterogeneous/diverse a group is, the more effective the decision will be, because different perspectives will be discussed, and incorrect answers not accepted (Johnson and Johnson 2009). Nevertheless, there are two sides of the coin. On the one hand, diversity can increase the group productivity, because of heterogeneous information and higher problem-solving potential. On the other hand, it can decrease the productivity, because of interruption and interpersonal conflicts (Collins and Guetzkow 1964). Gender diversity is linked to the question of whether a bias exists in a group and if it affects the group performance. Although respect for people is one cornerstone of Integrated Project Delivery (IPD), just last year, the first International Group for Lean Construction (IGLC) paper was published in the topic of gender and inclusiveness. For the paper, Arroyo et al. (2018) collected data using an online survey to understand if gender bias occurs in construction projects that apply Lean. The authors found that in general women feel more affected by positive or negative gender bias in comparison to men. Furthermore, almost $63 \%$ of the woman reported that their ideas are

5 Cohesiveness is the strongest root cause that leads to groupthink. It emerges when members of the group are friends, have positive attitudes concerning the group, high identification with and commitment to group values and goals (Forsyth 1990). 
not taken seriously. In depth, women commented that they were: ignored/not listened to, spoken over/interrupted, men repeated their idea and got support/credit for it, and not recognized for their idea. Moreover, $71 \%$ of female Lean practitioners reported that their ideas are not taken seriously. This might be due to their awareness of questioning the status to improvement (Arroyo et al. 2018). Reflecting on the results almost one year later, we argue that, because women's ideas are not taken seriously, their opinions might not be taken seriously either during group decision-making in the owner, architecture, engineering and construction (OACE) industry. In reference to the literature, our argumentation can be reinforced. For example, Johnson and Schulman (1989) conducted an experiment with students from UC Santa Barbara to analyze the effects of gender proportion in group decision-making. The students were divided into 85 four-person groups (15 only male, 16 only female, 15 with 3 men and 1 woman, 19 with 3 women and 1 man, 20 with 2 men and 2 women). Then a problem was handed to the groups on which they had to decide as a group within $30 \mathrm{~min}$. After they had made the decision, each member had to evaluate every other member- including him or herself - regarding task and socioemotional activity. The results showed that both men and women experienced gender bias when their sex was in the minority; the effects were to the disadvantage of the women and to the advantage of the men ${ }^{6}$ (Johnson and Schulman 1989). Elsass and Graves (1997) argue that the different communication style of women in a male-dominated group can "lead to underestimation of their capabilities" (p. 955) and a gender-related exclusion. Therefore, we argue that gender-diverse decision-making groups will make better decisions in construction projects.

\section{Choosing By Advantages}

CBA is a multi-criteria decision-making method developed by Suhr (1999) that is based on a logical and clear structured framework and uses well-defined vocabulary to differentiate between alternatives (Schöttle and Arroyo 2017). The high degree of transparency that CBA provides help teams understand each other's perspectives and preferences, and makes it easier to achieve consensus during decision-making based on holistic perception of value and not sub-optimization, which aligns with the Lean idea of making decisions slowly by consensus and implementing rapidly (nemawashi). Different studies have already shown that CBA leads to constructive conversations, less frustration during decision-making, confidence about the decision result, and is traceable for a not involved party (e. g. Arroyo et al. 2017; Schöttle and Arroyo 2017; Arroyo and Long 2018, Schöttle et al. 2018). Moreover, transparent documentation of the decision helps to create

6 For women the top score in task activity decreased with a decrease in number of women in the group. For men this only happened when one man was in the group, but the score was still above average. In comparison, women scored below average when they were the only woman in the group. As soon as men formed the majority in the group, the top score was unaffected. In the case of the lowest score, women achieved lower scores than men regardless of the gender composition. In the minority groups, the lowest men's score was significantly higher than the lowest women's score. Only in the homogeneous gender groups was the lowest score not significantly different. In the case of the socioemotional activities, the highest and lowest scores did not show any evidence of being impacted by gender. 
a shared understanding and trustful environment (Schöttle et al. 2018). The literature has not yet studied whether CBA encourages inclusiveness with regard to the three issues we have studied in the literature. This paper aims to fill that gap.

\section{RESEARCH METHODOLOGY FOR CASE STUDY}

The authors of this paper used different research approaches for the same project being studied. Action research was used to identify issues and intervene in the project based on findings (Dickens and Watkins, 1999). The action research involved surveys, discussions, meeting evaluation such as Plus Delta, and observations to improve the CBA training and facilitation. To determine the level of knowledge regarding Lean methods and tools such as CBA, a survey (Lean Awareness Survey) was sent to 267 members of the project team in November 2018. One hundred and sixty team members fully and 17 partly completed the survey. The main focus of the survey was not CBA, but the answers were used as indicators to improve the CBA implementation. In February 2019 another survey was handed out to the participants after a CBA session to deeply investigate if there is a difference regarding inclusiveness during decision-making when CBA is used as decisionmaking method or not, this time the authors used case study research approach for explanation building (Yin 2014). This survey focused on the topic of inclusiveness in decision-making by comparing decisions made with or without CBA (inclusiveness survey) by asking closed-ended and open-ended questions. Out of 15 participants, six completed the survey. The results of both surveys were then discussed with 10 trained CBA facilitators for a more general discussion on how well the surveys matched their perception and to incorporate this new knowledge into practice. Additionally, the CBA facilitators were encouraged to evaluate each CBA workshop with the participants in a Plus Delta exercise to improve practice. This feedback was also shared amongst the facilitators and is entered as data in this paper.

\section{CASE: LOWER THAMES CROSSING}

Lower Thames Crossing is a £5bn tunnel project beneath the River Thames east of London connecting Kent, Thurrock and Essex (north to south). The crossing under the Thames will be the longest road tunnel in the country and one of the largest bored tunnels in the world with a diameter of 16 meters. So far, it is the largest single road investment project in the UK. The Lower Thames Crossing will be open for traffic in 2027 and is currently in the preliminary design phase. During the preliminary design phase more than 650 people have been working full or part time in the integrated project team. The integrated design team consists of employees from the client, Highways England, and a Joint Venture between the engineering companies Jacobs, Arcadis and COWI. The gender split in the project team is $61 \%$ male, $27 \%$ female, $11 \%$ prefer not to say and $1 \%$ responded 'other'.

\section{IMPLEMENTATION OF CBA}

CBA was first initiated by the Lean manager in spring 2017 to assess a small set of complicated design decisions. The decisions consisted of several technical alternatives and required a cross-disciplinary assessment. During decision-making the decision-makers 
perceived CBA to be more efficient in comparison to decision-making in which CBA was not applied. More value-adding ideas were included, and the result of the decision was widely accepted by the team. Thus, these experiences led to the integration of CBA into the governance structure for the interdisciplinary assessment of alternatives.

Training of CBA facilitators started in spring 2018. To have a diverse facilitation team, facilitators were selected from different disciplines. By March 2019 the project had 15 trained CBA facilitators. In addition to the facilitation of the CBA workshops itself, facilitators identify decisions that need cross-disciplinary review and support an inclusive and structured process based on CBA. For complicated decisions or decisions which include several disciplines, it has been shown that three facilitators are needed in order to: (1) ensure progress, (2) make sure everyone is heard, and (3) to capture notes on the decision, actions, assumptions and risks. Until now (January 2019) approx. 25 CBA decision-making workshops have been held with support from one or more facilitators and an unknown number of decisions have been made without facilitation.

\section{Project Findings}

In the Lean Awareness survey, 26\% of respondents reported that they have participated in one or more CBA decisions. Some of the comments given in the survey mentioned CBA: CBA workshops are great for gaining consensus across the project; CBA resulted in better quality of the decision, better quality, efficiency, togetherness; shared objective; better culture, transparency, and integrity; recognition of expertise. Workshop evaluations (Plus Delta) showed that participants feel that everyone is heard, and that juniors found it easier to speak up compared to seniors. There is no directive leadership in the room during CBA workshops as everyone is seen as equal and influence depends on the knowledge the individual brings to the table. For some senior participants this can at first be challenging, while others feel empowered by this change of hierarchy and influence. Introvert personalities have pointed out that they appreciate being given the opportunity to prepare before presenting and discussing the issues. This preparation within their own discipline also mitigates the risk of groupthink where one influential voice in the room could impact the decision without having documentation to back it up.

The inclusiveness survey was conducted based on a single CBA decision and contained an equal number of participants regarding female and male genders. As the number of respondents is small, the results can be seen only as indicative. The CBA experience of the respondents varies, from experienced CBA facilitators, CBA facilitators in training and participants in CBA decision-making. The respondents mentioned the following pain points of decision-making in general ${ }^{7}$ : poor communication, lack of transparency, lack of clarity and common understanding, lack of technical understanding of decision-maker, very poor upward communication of pressing issues, lack of focusing on solving pressing issues, too much focus on meaningless reporting, poor documentation of exact decisions and the next steps to implement the decision, not identifying all appropriate stakeholders,

7 These statements reflecting on difference between CBA and traditional decision-making which is not clearly defined. The results do not conclude anything about the quality of decision-making in general on the project. 
missing inclusiveness, content quality against time, and not getting consensus on what the key criteria are, and their importance. The pain points go along with the situation where the participants agree to a group decision although they actually disagree with it. For those cases participants stated that they agreed, because it was easier to go along with the decision rather than admit that they did not understand it or that not all the information had been shared to enable them to do so. Furthermore, one survey participant stated that s/he just trusts others to make the right decision, because they have more experience. Based on the comments, it can be presumed that the decision-making was not transparent and understandable. Furthermore, disagreeing but accepting decisions when they make sense, leads to the question of the decision quality. One-third of participants answered the question of how easy it is to accept a decision when not using CBA with "don't know" and two-thirds with "moderate difficult". This is also an indicator for the lack in understanding due to communication, documentation or information sharing, and for a missing feedback loop.

Table 1: Overview of the inclusiveness survey respondents

\begin{tabular}{|c|c|c|}
\hline Gender & Project position & СВA experience degree \\
\hline Male & Workstream management/lead & $\begin{array}{l}\text { Facilitator of and participant of a } \\
\text { CBA decision-making session }\end{array}$ \\
\hline Female & Workstream management/lead & $\begin{array}{c}\text { Participant of a CBA decision- } \\
\text { making session }\end{array}$ \\
\hline Female & Workstream management/lead & $\begin{array}{c}\text { Participant of a CBA decision- } \\
\text { making session }\end{array}$ \\
\hline Female & Engineer/Consultant/Senior practitioner & $\begin{array}{c}\text { Facilitator of a CBA decision- } \\
\text { making session }\end{array}$ \\
\hline Male & Engineer/Consultant/Senior practitioner & $\begin{array}{l}\text { Participant in CBA training and } \\
\text { CBA decision-making session }\end{array}$ \\
\hline Male & External contractor & $\begin{array}{l}\text { Participant in CBA training and } \\
\text { CBA decision-making session }\end{array}$ \\
\hline
\end{tabular}

The results show that when not applying CBA people did not speak up as they do when using CBA (see Table 2). The survey participants mentioned that this is an issue of having the opportunity to be present during the process and having the feeling that their contribution is relevant. This goes along with experiences such as being ignored, not being heard, being spoken over or interrupted the survey participants had when CBA was not applied. These experiences influence the team member in the behaviour of speaking up. Furthermore, missing a logical frame and transparency results in a lack of interaction with each other's perspective as well as a missing facilitator that takes care of including every member of the decision-making group, especially regarding age bias. In comparison, when using CBA, survey respondents commented that they felt free to speak up, because the process encouraged and promoted speaking up, as well as including participants in group decision-making. The survey respondents also discovered that during the CBA session everyone involved spoke at least once and mainly for the same amount of time. This means 
that participants have a fair chance to speak up. One of the survey questions asked if the project provides an inclusive work environment regarding gender. All survey participants agreed that this is the case. Interestingly, only females reported that others repeated their own ideas and got support/credit for their ideas and that they do not feel they are recognized for their ideas when not using CBA. This aligns with the paper by Arroyo et al. (2018) and could be a sign of gender bias. Additionally, respondents agreed that the facilitator invited them to provide ideas, asked for the input of all team members, encouraged the members of the group decision-making to take the initiative, and valued the options of others equally. Thus, the facilitator played a key role in helping to include all group decision members during the CBA session.

Table 2: Summary of the inclusiveness survey results

\begin{tabular}{|c|c|c|}
\hline & Without using CBA & Using CBA \\
\hline Speak-up freely & $\begin{array}{l}\text { - Variation from occasionally to } \\
\text { always }\end{array}$ & - Yes \\
\hline $\begin{array}{l}\text { Respect } \\
\text { regarding views }\end{array}$ & $\begin{array}{l}\text { - High variation: somewhat agrees } \\
\text { to somewhat disagrees }\end{array}$ & - Yes \\
\hline Experience & $\begin{array}{ll}\text { - } & \text { Ignored/Not listened to } \\
\text { - } & \text { Spoken over/Interrupted } \\
\text { - } & \text { Not being included } \\
\text { - } & \text { Females reported that others } \\
& \text { repeated their idea and got } \\
& \text { support/credit for it, and they } \\
& \text { were not recognized for their idea }\end{array}$ & 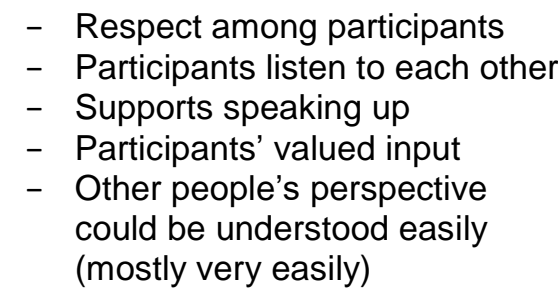 \\
\hline
\end{tabular}

\section{DISCUSSION}

Traditionally in the construction industry, decisions are perceived to be made subconsciously and based on a few influential voices. It is a part of the culture to make decisions quickly and confidently. The pain points of the respondents show clearly that the usual decision-making suffers, because of not having the right people in the room, a lack in communication and information sharing, and a misunderstanding of perspectives during and after the decision-making, which cause problems in understanding the decision result. The logical structure and the transparent documentation through the agreed process help the team to avoid group thinking and to create psychological safety, because the team creates awareness regarding interaction and their effect on decisions. Also, different perspective and inputs were valued when using CBA. As one respondent stated, CBA "promotes inclusivity by nature of the more open invitation process". Furthermore, participants of CBA sessions have a strong learning curve in preparing the decision, because they are aware of issues impacting the decision. It was also observed that the engagement in CBA was higher in the second session. Furthermore, CBA impacted other processes such as value management assessments. Having dedicated resources for facilitation might lead to more inclusiveness independent of the decision method in play. By having a structured process that is recognized, the decision owners can resist the 
urgency to take the decision on the spot in order to meet a deadline. The facilitators in the room also allow the decision owner to participate on equal terms. This also allows the disciplines to prepare arguments, which gives the opportunity to disagree about the most advantageous outcome of the decision and still reach a shared recommendation. One unique feature of CBA is that discussion is not about which factor is more important, like safety, time, quality, etc.; the discussion focuses on what relevant differences exist between the alternatives. This avoids many conversations when, for example, a discipline lead argues that his or her discipline is the most important when in fact there is no difference in how the alternatives perform.

At this point it cannot be stated whether CBA helps to overcome gender biases, and future research needs to address this. However, in discussions, the CBA facilitators keep mentioning that CBA is a better way than having no agreed decision process. The impact of group cohesiveness is also unclear. What can be said is that, because of different group constellations in decisions, the impact must vary from group to group. The inclusiveness survey as well as the input from CBA facilitators could be biased towards CBA, as this was the only known decision method in the project. The negative feedback on traditional decision-making should also be considered carefully as this might be the result of the specific decision in play and not a general picture of how well CBA works. Even though the results from the data analysis provide an insufficient dataset to conclude on inclusiveness, it can be used indicatively to point to future research questions.

\section{CONCLUSIONS}

Inclusiveness is key to proceeding effectively during decision-making and to get a highquality decision. CBA provides a strong structure and a logical manner that helps to understand the perspective of others, and indicates if information is missing or unclear. This helps to achieve a higher degree of inclusiveness. Based on the research it can be stated that the authors found evidence that CBA promotes inclusiveness to overcome groupthink and promotes psychological safety. The authors did not find direct evidence that CBA helps to overcome gender bias, but the CBA decision dynamic does allow everybody to speak up regardless of gender. Thus, more data is needed to confirm the presumptions. This paper is limited to one case study; therefore, more research to generalize findings is required.

\section{ACKNOWLEDGMENTS}

We would like to thank the project team at Lower Thames Crossing and especially the participants of the survey for providing their insights.

\section{REFERENCES}

Arroyo, P., Fuenzalida, C., Alberti, A., and Hallowell, M. (2016). "Collaborating in Decision Making of Sustainable Building Design: An Experimental Study Comparing CBA and WRC Methods." Energy and Building, 128(5), 132-142.

Arroyo, P., and Long, D. (2018). "Collaborative Design Decisions.” In: 26th Ann. Conf. of the Int. Group for Lean Construction. Chennai, India, 463-472. 
Collins, B.E., and Guetzkow, H. (1964). Social Psychology of Group Process for Decisionmaking. John Wiley \& Sons Inc., New York, NY.

Dickens, L., and Watkins, K., (1999). “Action Research: Rethinking Lewin.” Management Learning, 30(2), 127-140.

Edmondson, A. (1999). "Psychological Safety and Learning Behavior in Work Teams." Administrative Science Quarterly, 44(2), 350-383.

Ellis, D.G., and Fisher, A.B. (1994). Small Group Decision Making: Communication and the Group Process. $4^{\text {th }}$ ed., McGraw-Hill, New York, NY.

Elsass, P.M, and Graves, L.M. (1997). "Demographic diversity in decision-making groups: The experience of women and people of color." Academy of Management Review, 22(4), 946-973.

Forsyth, D.R. (1990). Group Dynamics. 2. ed., Brooks/Cole, Pacific Grove, CA.

Hirak, R., Peng, A.C., Carmeli, A., and Schaubroeck, J.M. (2012). "Linking leader inclusiveness to work unit performance: The importance of psychological safety and learning from failures." Leadership Quarterly, 23(1), 107-117.

Janis, I.L., and Mann, L. (1979). Decision Making: A Psychological Analysis of Conflict, Choice, and Commitment. Free Press, New York, NY.

Janis, I.L. (1982). Groupthink: Psychological Studies of Policy Decisions and Fiascoes. $2^{\text {nd }}$ ed., Houghton Mifflin, Boston, MA.

Johnson, D.W., and Johnson, F.P. (2009). Joining Together: Group Theory and Group Skills. 10. ed., Pearson, Upper Saddle River, NJ.

Johnson, R.A., and Schulman, G.I. (1989). "Gender-role composition and role entrapment in decision-making groups.” Gender \& Society, 3(3), 355-372.

Matthews, O., and Howell, G. A. (2005). Integrated project delivery an example of relational contracting. Lean Construction Journal, 2(1), 46-61.

Nembhard, I.M., and Edmondson, A. (2006). "Making it safe: The effects of leader inclusiveness and professional status on psychological safety and improvement efforts in health care teams." J. Organiz. Behav. 27, 941-966. DOI: 10.1002/job.413.

Patrick, H. A., and Kumar, V. R. (2012). Managing workplace diversity: Issues and challenges. Sage Open, 2(2), 2158244012444615.

Putnam, L.L., and Stohl, C. (1996). "Bona fide groups: An alternative perspective for communication and small group decision making." In: Hirokawa, R.Y., and Poole, M.S. (Eds.), Communication and Decision Making. Sage, Thousand Oaks, CA.

Randel, A.E., Dean, M.A., Holcombe Ehrhart, K., Chung, B., and Shore, L. (2016). "Leader inclusiveness, psychological diversity climate, and helping behaviors." Journal of Managerial Psychology, 31(1), 216-234.

Schöttle, A., and Arroyo, P. (2017). "Comparison of Weighting-Rating-Calculating, Best Value, and Choosing by Advantages for Bidder Selection." ASCE J. Constr. Eng. Manage., 143(8). https://doi.org/10.1061/(ASCE)CO.1943-7862.0001342.

Schöttle, A., Arroyo, P., and Christensen, R. (2018): "Demonstrating the Value of an Effective Collaborative Decision-Making Process in the Design Phase." In: 26th Ann. Conf. of the Int. Group for Lean Construction. Chennai, India, 899-909. 
Schöttle, A., Christensen, R., \& Arroyo, P.

Shore, L.M., Randel, A.E., Chung, B.G., Dean, M.A., Ehrhart, K.H., and Singh, G. (2011). "Inclusion and diversity in work groups: A review and model for future research." Journal of Management, 37(4), 1262-1289.

Suhr, J. (1999). The choosing by advantages decision-making system. Quorum, Westport. Yin, R.K. (2014). Case Study Research Design and Methods. 5th ed., Sage, Los Angeles, CA: Sage. 